\title{
Technogenic Coal Formations - Promising Raw Materials for Improvement of Mining and Processing Enterprises Energy Independence
}

\author{
Andrey Ushakov ${ }^{1}$, Elena Ushakova $^{1}$, Irina Bogolyubova ${ }^{1}$, and Gulnaz Alibaeva ${ }^{2}$ \\ ${ }^{1}$ T.F. Gorbachev Kuzbass State Technical University, 650000, 28 Vesennyaya St., Kemerovo, Russia \\ ${ }^{2}$ I. Razzakov Kyrgyz State Technical University, 720044, 66 Mira St., Bishkek, Kyrgyzstan
}

\begin{abstract}
There are coal-processing products (coal sludge, screening, dust, coke dust and fines) and organic waste (excess activated sludge, waste from water treatment plants) suggests using to produce energy gaseous in the paper. The optimal compositions of molded granules subjected to thermochemical processing to obtain synthesis gas are determined. The technological design of coal and organic waste joint processing has been developed. The main technological parameters of the processes are indicated and calculations of the main material flows are performed in accordance with the conditions of the processes.
\end{abstract}

\section{Introduction}

Currently, the extraction and processing of solid minerals is carried out on such a scale that the volume of waste generation and storage is approaching critical figures estimated at hundreds of millions of tons [1-6].

At the same time, the main waste mass is formed during coal transportation, enrichment, storage and processing. Considering the already accumulated waste volumes of this type (screenings, spills, slime, dust, etc.), it is obvious that they contain a significant organic mass and energy potential [7-9].

Russian Federation energy strategy for up to 2030 provides for an increase in the share of coal in the country's fuel balance. It will inevitably lead to the formation of new waste volumes.

Therefore, it is relevant to develop a combined technological scheme of technological process. There are the focus will be on the processing and energy use of carbon-containing substances fine fractions (coke dust, coal sludge, screening, etc.) in the scheme. At the same time, the involvement of organic biomass in such technology as a binder for initial mixture forming will allow efficient processing of two waste types in a single technological process [10].

Studies in this direction have shown that dehydrated excess activated sludge from municipal water treatment plants is the most effective binder for connecting small-scale fractions of coal mining and processing products. 


\section{Materials and methods}

If we consider the technological design of the proposed solutions, we can distinguish several main stages that need to be implemented for the processing of the above-mentioned waste.

There is a description of the scheme for the joint use of coal processing products and organic waste is presented in figure 4.

According to this scheme, the mechanically dewatered excess activated sludge from the warehouse is fed to the hopper with feeder 1 . The required volume of excess activated sludge (EAS) is dosed using the feeder. The EAS after the belt feeder and water from the reservoir 15 arrive in the mixing unit 2.

The dosage operates automatically to achieve optimal humidity of the mixture. Gerotor pump 12 delivers the resulting mixed mass to the tank 3 .

There are, mixing periodic process of the fermented mass is organized in the methane tank. An important parameter of this process is the temperature of the mixture, which the most comfortable environment for anaerobic bacteria. To reduce fluctuations in the ambient air temperature, the external finishing of the methane tank is provided with a heatinsulating material.

Mesophilic temperature $\left(40{ }^{\circ} \mathrm{C}\right)$ is the most suitable for anaerobic digestion organic substances. To control temperature changes, thermocouples are provided, and pressure gauges control the pressure.

The mixing unit 2 is fed with biomass, as well as solid coal waste from the hopper 1. to obtain a mixture of the desired consistency, this unit is fed with water from the container 15.

The mixture of the required humidity and consistency is sent to a drum granulator, whose rotation speed varies from 20 to $45 \mathrm{rpm}$. Research has shown that the most suitable mode for forming fuel pellets is $11-18 \mathrm{rpm}$. The formed fuel is sent to dry. The supply of hot coolant for drying to the device is made by means of an air compressor 10. Air from the compressor enters the heater 17 , where it is heated by heat exchange with water from the cogeneration center.

Further, the dried fuel pellets are fed by a belt conveyor 11 to the receiving hopper for pellets, from which they are sent to the gasifier 7 , the heating rate of the gasifier is $5-7{ }^{\circ} \mathrm{C}$ per minute, the duration of the high-temperature process is $2-3$ hours. Also, this gasifier is supplied with an oxygen vapor blast from the gas receiver 21 . This receiver is used as a storage device for storing a mixture of gases under pressure, as well as for smoothing gas pressure differences.

After conducting the high-temperature gasification process, in addition to the released synthesis gas, which is then sent for cooling to the freezers, in the lower part of which the condensate trap 19 is mounted, and the condensate accumulates in the collection container 18 , a solid product is also released-ash, which is removed from the lower part of the gasifier to the ash collection container 16 .

After that, the cooled synthesis gas to a temperature of $25-30{ }^{\circ} \mathrm{C}$ enters the final cleaning in the scrubber 9.

For the supply of technological equipment and heating of premises, biogas obtained at the first stage of obtaining the finished product is used, which is sent to the cogeneration center 4 for generating heat and electricity.

The hardware design of this technological scheme shows that in the process of joint processing of waste from mining and processing of coal, classic basic chemical devices (anaerobic digestion, energy generator, granulator, gasifier, receiving container for ash, scrubber), which can be combined as a single modular unit for more mobile transportation to the place of use. 


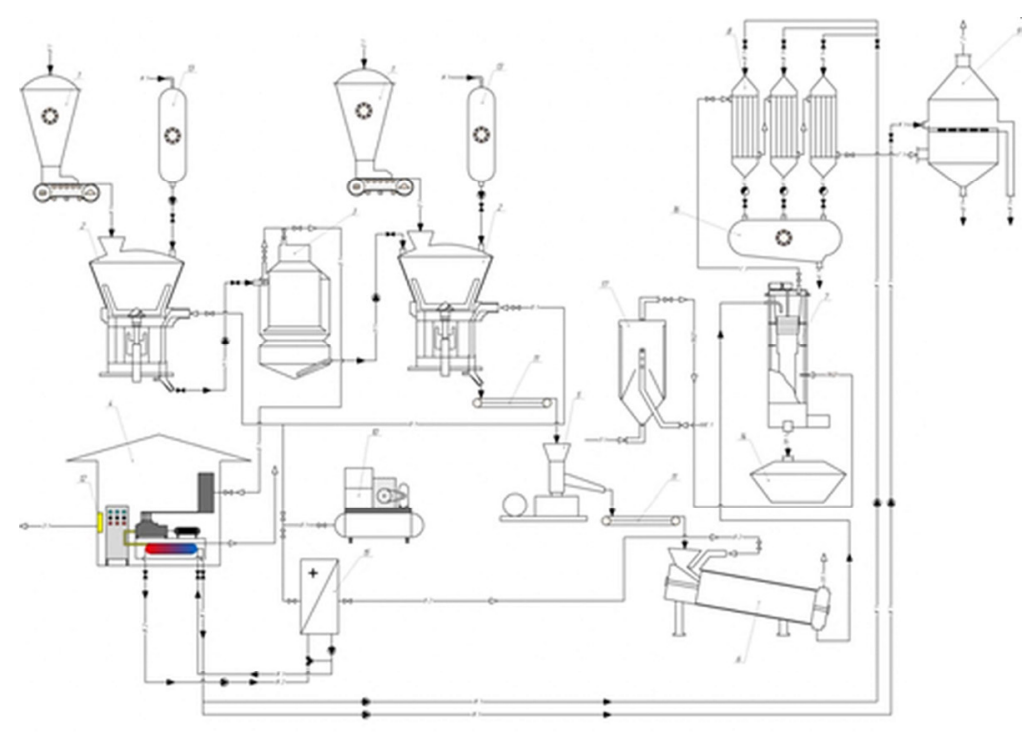

Fig 1. Hardware design of energy resources obtaining from coal and biomass: 1 - receiving hopper with a conveyor, 2 - mixer, 3 - anaerobic digestion, 4 - energy generator, 5 - granulator, 6 - semi product dryer, 7 - gasifier, 8 - receiving container for ash, 9 - scrubber, 10 - compressor, 11 - conveyor, 14 - transformer, 15 - water tank, 16 - ash collection container, 17 - heater, 18 - condensate receiver, 21 - device for continuous mixing. Lines: -I1 - excess activated sludge, -W1 - cold water, W2 - hot water, -B1 -biogas,-M1 - biomass, -O1 - coal waste, -T1 - fuel pellets, -T2 - dry fuel granules,-A1 - air, -A2 - hot air, -G1 - synthesis gas, -G2 - purified gas, -Q1 - heat from combustion, -W3 - condensate, -WG1 - coolant, -HW1 - solid residue, -E1 - electricity, -A1 - sludge, -VO1 - oxygen vapor blast, -V1-steam, -O - oxygen.

\section{Results and discussion}

Laboratory studies of gaseous energy carrier production in accordance with the above scheme have shown that the synthesis gas can be used for generating thermal energy, and its composition depends significantly on the technological parameters of the granulation process and high-temperature processing.

The calculation of material flows is the main stage of evaluating the effectiveness of the technological process and the prospects for its further implementation.

To do this, we will use the method of calculating the material balance, which reflects the degree of elaboration of the processes. As initial data (tables 1,2) for material calculations, we take the annual productivity for the target product $-60 \mathrm{~m}^{3} / \mathrm{h}$ of synthesis gas, as well as the composition of the initial substances, the yield for the main and side reactions-in accordance with the experimental data obtained earlier (table 3 ). 
Table 1. Initial data for calculating material flows at the stage of producing gaseous fuel (synthesis gas).

\begin{tabular}{|l|c|}
\hline \multicolumn{1}{|c|}{ Indicator } & Value \\
\hline $\begin{array}{l}\text { Synthesis gas temperature at the reactor outlet, } \\
{ }^{\circ} \mathrm{C}\end{array}$ & $830-850$ \\
\hline $\begin{array}{l}\text { The equilibrium composition of synthesis gas } \\
\text { for steam-oxygen blown, vol. } \%\end{array}$ & $\begin{array}{l}\mathrm{H}_{2}-31.0 \ldots 31.4 \\
\mathrm{CO}-68.6 \ldots 68.9\end{array}$ \\
\hline
\end{tabular}

Table 2. Technical analysis of raw materials - organic waste and coal processing products.

\begin{tabular}{|l|c|c|c|}
\hline \multicolumn{1}{|c|}{ Waste } & W, $\%$ & $\mathbf{A}^{\mathbf{a}}, \mathbf{\%}$ & $\mathbf{V}^{\text {daf }}, \mathbf{\%}$ \\
\hline 1. Coal waste: & & & \\
\hline 1.1 coal mining companies & $21.5 \pm 0.2$ & $35.7 \pm 0.3$ & $17.9 \pm 0.4$ \\
\hline 1.2 coke enterprise & $19.3 \pm 0.1$ & $27.1 \pm 0.2$ & $13.5 \pm 0.3$ \\
\hline 2. Coal processing waste: & & & \\
\hline 2.1 coke dust & $17.3 \pm 0.2$ & $35.2 \pm 0.3$ & $15.7 \pm 0.3$ \\
\hline 2.2 coke fines & $19.5 \pm 0.2$ & $33.4 \pm 0.2$ & $15.4 \pm 0.2$ \\
\hline
\end{tabular}

The influence of the initial mixture composition on the yield and the percentage of components in the resulting gaseous product is established. The granulation stage is implemented to regulate the ratio of carbon-containing waste in the technological process. The composition of the obtained granules subjected to further thermochemical processing is shown in table 3.

Table 3. Composition of pellets subjected to thermochemical processing to produce gaseous fuel.

\begin{tabular}{|l|c|c|}
\hline \multirow{2}{*}{$\begin{array}{c}\text { Type of carbon-containing } \\
\text { filler }\end{array}$} & \multicolumn{2}{c|}{ Composition of the granulated mixture, \% mass. } \\
\cline { 2 - 3 } & filler & binder \\
\hline Coal waste & $60-65$ & $35-40$ \\
\hline Coal processing waste & $45-40$ & $55-60$ \\
\hline
\end{tabular}

The calculation was based on classical reactions of solid carbon-containing substances gasification process. There are data obtained in tables 4 and 5 .

Table 4. The material stage balance of fuel granules formation.

\begin{tabular}{|c|c|c|c|}
\hline \multicolumn{2}{|c|}{ Consumption } & \multicolumn{2}{|c|}{ Receiving } \\
\hline component & $\mathrm{kg} / \mathrm{h}$ & component & $\mathrm{kg} / \mathrm{h}$ \\
\hline 1. Filler, including & 19.0 & \multirow{3}{*}{ 1. Fuel pellets } & \multirow{3}{*}{21.3} \\
\hline dry coal waste & 14.3 & & \\
\hline water & 4.7 & & \\
\hline 2. Binder, including & 54.5 & \multirow{2}{*}{ 2. Free water } & \multirow{2}{*}{52.2} \\
\hline dry binder & 7.0 & & \\
\hline
\end{tabular}




\begin{tabular}{|l|l|l|l|}
\hline water & 47.5 & & \\
\hline Total & 73.5 & Total & 73.5 \\
\hline
\end{tabular}

Table 5. The material stage balance of gaseous fuel production (synthesis gas).

\begin{tabular}{|c|c|c|c|c|c|c|c|}
\hline \multicolumn{4}{|c|}{ Consumption } & \multicolumn{5}{c|}{ Receiving } \\
\hline component & $\mathrm{m}^{3} / \mathrm{h}$ & $\mathrm{kg} / \mathrm{h}$ & vol. \% & component & $\mathrm{m}^{3} / \mathrm{h}$ & $\mathrm{kg} / \mathrm{h}$ & vol. \% \\
\hline $\mathrm{C}$ & - & 21.3 & - & $\mathrm{C}$ & - & 2.1 & - \\
\hline $\mathrm{O}_{2}$ & 11.8 & 37.7 & 37.9 & $\mathrm{~N}_{2}$ & 0.1 & - & - \\
\hline $\mathrm{H}_{2} \mathrm{O}$ & 19.3 & 61,9 & 63.1 & $\mathrm{H}_{2}$ & 19.3 & - & 31.1 \\
\hline $\mathrm{N}_{2}$ & 0.1 & 0.4 & - & $\mathrm{CO}$ & 42.9 & - & 68.9 \\
\hline
\end{tabular}

\section{Conclusion}

To sum up, several conclusions can be draw:

1. The calculation of material flows coal products and organic waste processing technology is carried out.

2. Hardware design of the technological scheme is performed. The proposed solutions will involve fine fractions of carbon-containing substances (coke dust, coal sludge, screening, etc.) in the processing.

3 . It is noted that the placement of this type installations does not require significant capital investment and can be implemented on the premises of existing enterprises that have appropriate carbon-containing waste in their technological cycle. This will contribute to a positive economic effect in the form of a reduction in the energy carriers consumption of traditionally used for the company's activities.

\section{References}

1. D. Yu. Savon, A. V. Zhaglovskaya, A. E. Safronov, D. Sala, Eurasian Mining, 1, 8-10, DOI: $10.17580 / \mathrm{em} .2018 .01 .02$ (2018)

2. C. A. I. Raju, M. Nunela, D. Prabhakar, et al. International Journal of Research in Engineering and Technology, 3(2), 54-63 (2014)

3. M. A. Brand, R. C. Jacinto, R. Antunes, Renewable energy, 111, 116-123 (2017)

4. S. K. Guttikunda, P. Jawahar, Atmospheric Environment, 92, 449-460 (2014)

5. A. M. Musalam, A.Fattah, A. Qaraman, International Journal of Energy and Environmental Research, 4, 27-36 (2016)

6. T. Takeshita, K. Yamaji, Environmental Economics and Policy Studies, 8:1, 55-87 (2014)

7. S. Belošević et al., Applied Thermal Engineering, 74, 102-110, (2015)

8. O. Ozbakir, S. Koltka, E. Sabah, Particulate Science and Technology, 35(6), 712-722, (2017)

9. W.Chen, R. Xu, Energy Policy, 38:5, 2123-2130 (2010)

10. S. A. El-Sayed, M. E. Mostafa, Energy Conversion and Management, 85, 165-172 (2014) 